\title{
Penerapan Teknik Penggambaran Garis Kontur Menggunakan Auto Cad 3D
}

\author{
Novatus Senduk \\ Program Studi Konstruksi Bangunan Gedung \\ Jurusan Teknik Sipil Politeknik Negeri Manado \\ e-mail: novatussend@yahoo.com
}

\begin{abstract}
Abstrak
Saat ini teknologi sudah semakin maju, dalam setiap bidang kerja telah menggunakan komputer yang dijadikan alat yang membantu mempermudah pekerjaan. Salah satu alat yang membantu mempermudah pekerjaan dibidang komputer adalah C.A.D (Computer Aided Design ) atau Disain dengan bantuan Komputer, yang bertujuan untuk memudahkan para perancang dan juru gambar dalam menuangkan idenya secara visual dalam tampilan obyek gambar. Dengan adanya penelitian ini akan diperoleh pemahaman dan langkah-langkah menggambar garis kontur dengan menggunakan software AutoCAD, kemudian divisualisasikan kedalam bentuk yang nyata secara 3 dimensi, menghitung volume hasil penggambaran dan mengetahui kendala yang ada dalam menerapkan penggambaran garis kontur. Metode penelitian yang akan dipakai adalah metode penelitian praktek ditinjau dari tempatnya, suatu pendekatan praktek, yaitu suatu penelitian dilakukan di laboratorium yaitu laboratorium komputer/laboratorium Gambar dengan tidak menutup kemungkinan termasuk menggunakan tempat lain yang menyediakan fasilitas komputer. Hasil penelitian menggambar garis kontur yang cepat dan praktis adalah menggunakan Auto CAD 3D yang memperlihatkan visualisasi gambar 3 dimensi secara nyata.
\end{abstract}

Kata kunci ; garis, kontur, Auto CAD

\begin{abstract}
Nowadays, technology is increasingly advanced. In every field of work, computers are used as tools that help make work easier. One of the tools that help facilitate work in computers is C.A.D (Computer-Aided Design) or Computer Assisted Design, which aims to make it easier for designers and drafters to express their ideas visually in the appearance of image objects. With this research, understanding, and steps to draw contour lines using AutoCADsoftware are obtained, then visualize it into a simple form in 3 dimensions, calculate the drawing volume, and find out the obstacles in applying contour line drawing. The research method used is a practical in terms of its place, namely research conducted in a laboratory, and a computer laboratory/drawing laboratory that provide computer facilities. The research results to draw contour lines that are fast and practical using Auto CAD 3D, which shows accurate 3dimensional image visualization.
\end{abstract}

Keywords ; line, contour, Auto CAD 


\section{PENDAHULUAN}

Catatan paling dini yang diciptakan manusia ialah grafik yang melukiskan orang, rusa, banteng dan binatang lainnya pada dinding gua. Gambar ini memuaskan suatu kebutuhan dasar bagi pengungkapan jauh sebelum berkembangnya tulisan. Kebanyakan diantara gambar yang sangat dini itu dan yang sekarang masih ada, dibuat diatas perkamen, yang sangat tahan lama. Kemudian selama abad kedua belas, kertas dikembangkan di Eropa dan secara umum dipergunakan untuk membuat gambar. Dari gambar yang paling dini itu tentang benteng, bangunan dan mekanisme sederhana, dewasa ini hanya sedikit yang masih ada. Diantaranya yang kita jumpai sebagian besar berwujud pelukisan dan terdapat sebagai ukiran dan lukisan pada dinding konstruksi bangunan atau ditenun dalam permadani (Luzadder, Hendarsin, 1986). Karena para drafter diperhadapkan dengan tugas dalam menggambar bentuk obyek tiga dimensional pada media gambar, maka jelaslah bahwa teknik penggambaran yang telah mendapat pengakuan harus dijadikan rujukan agar gambar maupun sketsa yang dibuat dapat dengan mudah dimengerti.

Perancang tapak harus bekerja dalam ruang tiga-dimensi, yang dikemukakan dalam model-model atau pada gambar-gambar rencana dua-dimensi. Dimensi ketiga dinyatakan dalam rencana gambar dengan menggunakan isolin (garis-garis yang jaraknya sama) yang disebut "garis kontur". Garis kontur menyatakan suatu ketinggian dari atas permukaan air laut rata-rata dan digambar pada interval yang sama untuk membuat suatu peta topografi (Snyder, Catanese, 1984). Dalam gambar teknik terdapat bagian penggambaran tiga dimensi dengan teknik-teknik tertentu untuk menghasilkan sebuah gambar garis kontur.

Gambar garis kontur dalam keteknikan mempunyai peranan penting khususnya dalam memberikan informasi terhadap para pembaca gambar, pelaksana pekerjaan, pengembang dan sebagainya, untuk memberikan gambaran visual yang jelas baik secara dua-dimensi maupun tiga-dimensi tentang bentuk ketinggian permukaan tanah serta membuat perhitungan volume suatu keadaan permukaan tanah. Penggambaran secara tiga-dimensi akan memberikan nilai tambah bagi pembacaan tinggi rendahnya permukaan tanah serta visual yang memberikan gambaran secara realistik, sehingga akan mempermudah perancang atau pengembang lahan dalam menentukan rencana pengelolaan permukaan tanah selanjutnya baik dalam bentuk informasi lahan yang kemudian dilanjutkan dengan analisa tapak. Garis kontur adalah metode yang banyak dilakukan untuk menggambarkan bentuk ketinggian permukaan tanah di peta, karena memberi lebih presisi baik.

Menurut Iskandar Muda (2008), garis kontur adalah sebuah garis imajiner di lapangan menghubungkan dengan ketinggian atau garis kontur yang sama adalah garis kontinu di atas peta menunjukkan titik pada peta dengan sama tinggi. Baris nama lain kontur adalah tahapan, garis tinggi, dan garis ketinggian horizontal. Untuk garis kontur $+25 \mathrm{~m}$, berarti garis kontur tersebut terhubung dengan titik dengan ketinggian + yang sama $25 \mathrm{~m}$ hingga ketinggian tertentu. Garis kontur disajikan pada peta untuk ditampilkan pasang surut dari kondisi permukaan tanah. Selanjutnya aplikasi garis kontur adalah untuk untuk mendapatkan informasi tentang rata-rata kemiringan tanah, potongan profil permukaan memanjang atau melintang tanah pada proyek (bangunan) serta perhitungan penggalian dan tumpukan (potong dan mengisi) permukaan tanah asal terhadap ketinggian garis atau bangunan vertikal. Garis kontur bisa dibuat dengan membuat proyeksi garis vertikal persimpangan bidang horizontal dengan permukaan bumi ke bidang horizontal peta. Karena pada umumnya peta dibuat menggunakan 
skala pasti, maka garis kontur ini akan juga mengalami pengurangan sesuai dengan skala peta. Berikut ini adalah contoh gambar garis kontur tampak atas disertai dengan gambar potongan untuk menggambarkan permukaan secara dua-dimensi.

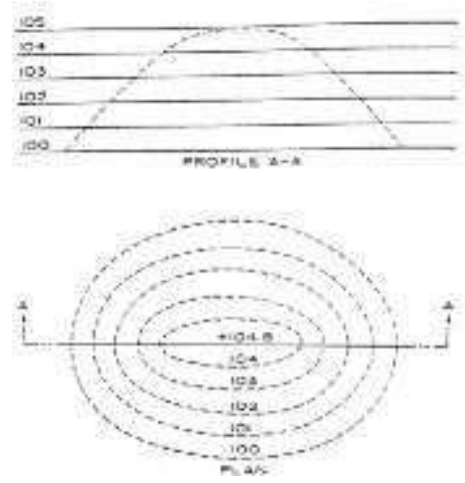

Gambar 1. Garis kontur yang menunjukan slope rata

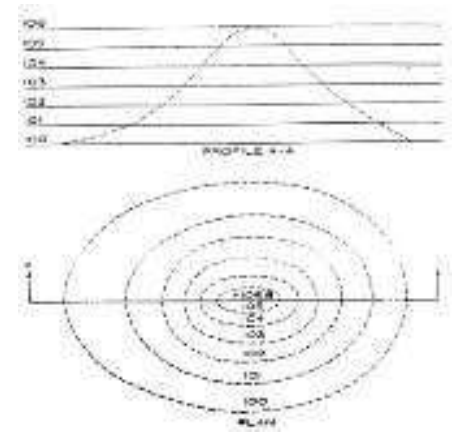

Gambar 2. Garis kontur yang menunjukan slope cekung

AutoCAD merupakan sebuah program CAD yang sangat terkenal dan familier dewasa ini, karena menawarkan berbagai kemudahan dan keunggulan yang bisa mempermudah kerja designer dan drafter dalam memvisualisasikan gagasannya. Sejak dibuat oleh Autodesk Corporation pada tahun 1982 hingga dikeluarkannya release yang terbaru, AutoCAD mengalami kemajuan dan perkembangan yang sangat berarti serta memiliki peran yang sangat besar dalam perkembangan desain saat sekarang. AutoCAD adalah software aplikasi yang dipakai untuk membuat desain gambar, seperti gambar-gambar sipil, arsitektur, elektro, mesin dan sebagainya, yang mana software AutoCAD memiliki kemudahan serta keunggulan dalam membuat gambar-gambar secara cepat dan presisi serta bisa dipakai untuk memodifikasi(modify) gambar dengan cepat.

Penggambaran garis kontur menggunakan aplikasi AutoCAD bisa menjawab kebutuhan penyajian visual garis kontur secara tiga-dimensi secara cepat dan akurat tanpa mengabaikan kaidah-kaidah gambar teknik. Selain itu kemungkinan penyajian visual secara tiga-dimensi dari berbagai arah pandangan sesuai penempatan kamera yang diinginkan perancang atau drafter dapat dilakukan menggunakan aplikasi AutoCAD. Kebutuhan perhitungan volume lahan yang dipakai dalam perhitungan Rencana Anggaran Biaya dapat dilakukan secara cepat dan akurat mendekati volume lahan yang sebenarnya sehingga kesalahan estimasi biaya dapat dihindari.

Beragam instruksi dan langkah-langkah harus dilakukan untuk mendapatkan hasil penggambaran maksimal yang menjadi salah satu point penting dalam pelaksanaan penelitian ini. Dari hasil-hasil yang didapat dalam penelitian ini diharapkan akan diperoleh manfaat sebagai berikut: 
1. Diperoleh langkah-langkah Teknik Penggambaran Garis Kontur Menggunakan Auto Cad 3d.

2. Diperoleh teknik penggambaran yang mudah dan cepat membuat gambar garis kontur yang bisa menjawab kebutuhan pengguna gambar teknik.

3. Diketahui kendala menggambar garis kontur menggunakan AutoCAD.

4. Memudahkan para drafter maupun mahasiswa dalam menggambar kontur.

5. Menjadi masukan untuk kegiatan praktek gambar teknik yang efektif.

6. Sebagai sarana untuk meningkatkan daya pikir para drafter maupun mahasiswa yang mempelajari gambar teknik.

Penelitian ini dilakukan dengan tujuan sebagai berikut:

Memahami tentang penggambaran garis kontur beserta elemennya menggunakan kaidah gambar teknik dengan lengkap dan benar.

1. Menjelaskan langkah menggambar garis kontur menggunakan software Auto CAD.

2. Menunjukkan visualisasi gambar 3 dimensi secara nyata sekaligus menghitung volume hasil penggambaran.

3. Mengetahui kendala yang ada dalam menerapkan penggambaran garis kontur dengan menggunakan software Autocad.

\section{DASAR TEORI}

Dalam dunia modern saat ini salah satu yang memiliki peran yang sangat besar adalah gambar. Dengan gambar, peran seorang ahli teknik, para desainer komunikasi visual, dan setiap orang yang berada dalam kehidupan masyarakat yang sangat kompleks seperti sekarang ini sangat dipermudah. Menggambar merupakan upaya mengkomunikasikan isi pikiran. Setiap gagasan yang diwujudkan dalam gambar akan memudahkan orang untuk menjelaskan, menguraikan, dan memaparkan setiap gagasannya. Menurut Eisuke Tanaka (1989) bahwa gambar presentasi memiliki suatu makna yang lebih luas dari hal tersebut. Penyajian visual berupa gambar dwi-matra (2 dimensi), digunakan dalam spektrum desain komunikasi visual baik di bidang bisnis, politik, sosial, industri, pertahanan-keamanan, pendidikan, dan organisasiorganisasi kemasyarakatan lainnya.

Sejak manusia tinggal di gua-gua, gambar merupakan kristalisasi peristiwa dan gagasan diluar diri manusia (Laseau, 1980). Melalui media gambar dunia batin, mitos, angan-angan dapat direalisasikan. Gambar sebagai ungkapan pikiran telah menjadi bagian penting dari kehidupan umat manusia. Konsep terbang pun diwujudkan dalam sketsa-sketsa setelah manusia 'melihat' burung terbang di angkasa, menginginkan untuk dapat terbang pula. Indra penglihatan merupakan indera yang memberi informasi yang cepat dan lengkap. Selain memanfaatkan mata sebagai sarana utama untuk memahami dunia, manusia menterjemahkan informasi yang diterima oleh indera lain kedalam kesan penglihatan. Paul Laseau (1980) memperkirakan bahwa 70\%-80\% dari pengetahuan manusia diperoleh lewat indera mata. Karena para drafter dihadapkan pada tugas untuk menggambar bentuk dan ukuran obyek tiga dimensional pada media gambar, maka jelaslah bahwa teknik penggambaran yang diakui harus diikuti apabila gambar atau sketsa mereka harus dimengerti dengan mudah.

Perancang tapak harus bekerja dalam ruang tiga-dimensi, yang dikemukakan dalam model-model atau pada gambar-gambar rencana dua-dimensi. Dimensi ketiga dinyatakan dalam rencana gambar dengan menggunakan isolin (garis-garis yang jaraknya sama) yang disebut "garis kontur". Garis kontur menyatakan ketinggian dari atas permukaan air laut rata-rata dan digambar pada interval yang sama untuk membuat suatu peta topografi (Snyder, Catanese, 1984).

Jurnal Teknik Sipil Terapan (JTST), e-ISSN 2714-7843 
Untuk membuat rencana tapak seorang perencana harus memahami sifat-sifat kontur. Kontur akan membantu perencana dalam memvisualisasikan bentuk lahan secara tiga-dimensi. Data kontur menunjukan ketinggian topografi yang ada, dan dinyatakan dalam bentuk peta yang akan memperlihatkan karakteristik tapak. Kontur adalah garis-garis yang menghubungkan titik-titik yang sama ketinggiannya di atas suatu bidang referensi (Rubenstein, 1989).

Garis kontur adalah metode yang memberikan ketelitian lebih baik, dilakukan untuk menggambarkan bentuk suatu permukaan tanah dan ketinggian permukaan tanah pada peta. Cara lain yang digunakan untuk menggambarkan permukaan tanah adalah dengan teknik hachures dan shading. Menurut Iskandar Muda (2008), sifat-sifat yang dimiliki garis kontur adalah sebagai berikut : a). Berbentuk kurva tertutup; b). Tidak bercabang; c). Tidak berpotongan; d). Jika melewati sungai menjorok kearah hulu; e). Jika melewati permukaan jalan menjorok kearah jalan menurun; f). Jika melewati bangunan tidak tergambar; g). Keadaan permukaan tanah yang terjal ditunjukan dengan garis kontur yang rapat; h). Keadaan permukaan yang landai ditunjukan dengan garis kontur yang jarang; i). Skala peta yang disajikan menentukan penyajian interval garis kontur, jika datar maka interval garis kontur adalah 1/1000 dikalikan dengan nilai skala peta, jika berbukit maka interval garis kontur adalah 1/500 dikalikan dengan nilai skala peta dan jika bergunung maka interval garis kontur adalah 1/200 dikalikan dengan nilai skala peta; j). Penyajian indeks garis kontur pada daerah berbukit adalah setiap selisih 4 garis kontur, pada daerah datar adalah setiap selisih 3 garis kontur, sedangkan pada daerah bergunung adalah setiap selisih 5 garis kontur; k). Satu ketinggian tertentu diwakili satu garis kontur; 1). Garis kontur yang lebih tinggi dikelilingi garis kontur berharga lebih rendah; m). Punggungan gunung ditandai rangkaian garis kontur yang berbentuk huruf "U"; n). Lembah/jurang ditandai suatu rangkaian garis kontur yang berbentuk huruf "V".

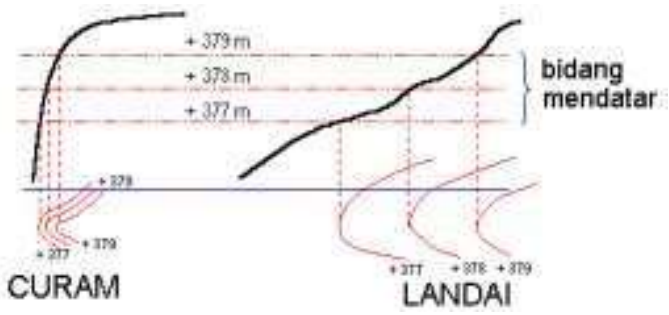

Gambar 3. Kerapatan garis-garis kontur di daerah landai dan curam

Akhir teknologi memungkinkan proses menggambar menjadi lebih mudah. Untuk membuat komunikasi dengan bahasa gambar menjadi lebih efisien, sangat diperlukan keberadaan komputer yang dilengkapi software aplikasi untuk mendesain gambar. Mempermudah penyimpanan arsip-arsip gambar, waktu yang diperlukan untuk mengambar lebih singkat, dan ringkas. Bersamaan dengan AKHIR teknologi, standar gambar juga telah dipaksa mengikutinya. Peluang munculnya teknologi baru untuk memenuhi kebutuhan merupakan tuntutan dunia usaha/dunia industri yang selalu berkembang dan persaingan dalam produk dan jasa. Perusahaan software di Amerika, AUTODESK telah membuat perangkat lunak untuk membantu perancangan/penggambaran yaitu Computer Aided Design (CAD).

Rio Manullang (2014), mengemukakan sebuah perangkat lunak komputer yang handal dalam membuat desain baik 2 dimensi (2D) ataupun 3 dimensi (3D) yaitu softwareAutoCAD yang dirancang untuk membantu para praktisi dalam bidang arsitektur, teknik sipil, desain interior bagi mahasiswa/siswa STM dalam membuat tugas dan pekerjaan yang berhubungan dengan perancangan bangunan baik itu membuat gambar bangunan kantor, rumah, apartemen maupun bangunan jembatan. keuntungan penggunaan Autocad adalah gambar lebih cepat diselesaikan dibanding kalau secara manual dan perubahan gambar dapat segera diganti. Ada beberapa alasan mengapa kita perlu mempelajari AutoCAD (Soma, 1999):

1) AutoCAD memiliki tingkat keakuratan yang cukup tinggi dan lebih terjamin dibanding menggunakan 
cara manual; 2) fasilitas penggambaran dan pengeditan yang semakin sempurna menjadikan AutoCAD mampu menghasilkan gambar yang jauh lebih cepat; 3) Perintah untuk mengedit memungkinkan gambar untuk direvisi dan diperiksa sebelum dicetak atau diprint; 4) AutoCad memiliki ruang kerja yang tidak terbatas dengan koordinat sepuluh pangkat sembilan puluh sembilan, dengan demikian gambar dapat dibuat sebesar yang kita butuhkan dan sebanyak apapun dalam ruang yang sama. Gambar juga dapat dicetak sebagian-bagian dengan skala yang tepat; 5) AutoCad juga memungkinkan gambar untuk dicetak berulangkali dengan skala yang berbeda tanpa harus membuat ulang; 6) Dengan sistim penyimpanan file, hasil gambar dapat disimpan secara permanen..

\section{METODE PENELITIAN}

Metode penelitian yang akan dipakai adalah metode penelitian praktek ditinjau dari tempatnya sebagaimana dijelaskan oleh Prof. Dr. Suharsimi Arikunto dalam bukunya berjudul Prosedur Penelitian (2010), Suatu pendekatan praktek, adalah suatu penelitian yang dilakukan di laboratorium yaitu laboratorium komputer/laboratorium Gambar dengan tidak menutup kemungkinan menggunakan tempat lain yang menyediakan fasilitas komputer/mesin gambar. Pada awal penelitian dilakukan persiapan peralatan berupa komputer dengan spsifikasi minimal intel processor core i3 @ $2.5 \mathrm{Ghz}, \mathrm{RAM} 2 \mathrm{~Gb}$, HDD $500 \mathrm{~Gb}$ dan di lengkapi dengan perangkat lunak OS windows 7, AutoCAD R 2012.

Langkah-langkah penelitian adalah :

1. Pengumpulan data.

Pengumpulan data kontur dilakukan dengan cara pengambilan sampel hasil pengukuran topografi dari literatur/sumber yang ada.

2. Analisa.

Data-data yang diperoleh dianalisa dalam bentuk :

- Menguji coba langkah penggambaran garis kontur

- Melihat proses dan hasilnya

- Menampilkan beberapa visualisasi terbaik

- Menghitung volume hasil penggambaran

3. Kesimpulan dan Solusi.

- Ditarik kesimpulan langkah penggambaran garis kontur yang efisien dan efektif.

- Visualisasi gambar 3 dimensi secara nyata.

- Hasil perhitungan volume

- Mengatasi kendala

\section{HASIL DAN PEMBAHASAN}

Instruksi penggambaran Kontur dengan AutoCAD.

Untuk data kontur dilakukan dengan cara pengambilan sampel hasil pengukuran topografi lahan kampus Politeknik Negeri Mando. 


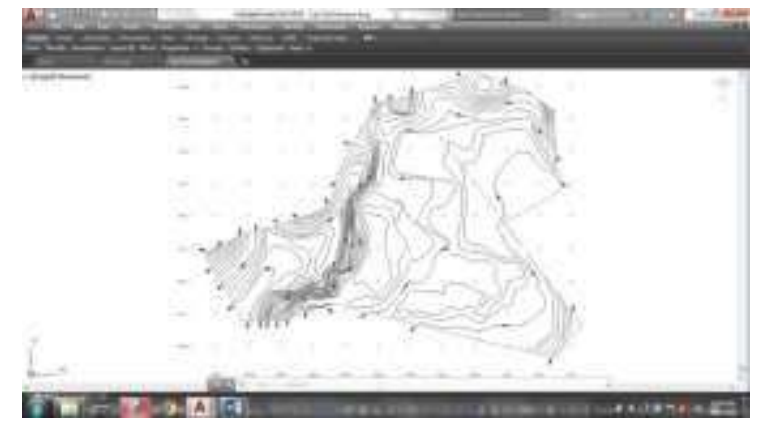

Instruksi penggambaran Kontur (Omura, Brian, 2017) :

Menggambar garis kontur per panel kontur (interval kontur)

PLINE at the command prompt

Command : PLINE or PL

Specify start point:

Current line-width is 0.0000

Specify next point or [Arc/Halfwidth/Length/Undo/Width]:

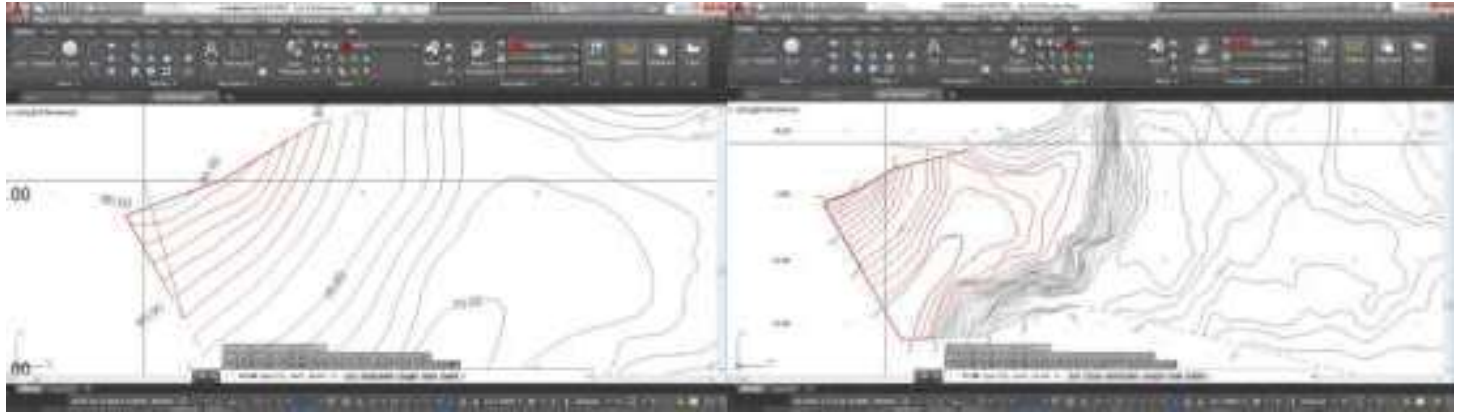

Setelah penggambaran interval kontur, dilakukan penyatuan garis-garis dalam satu interval kontur.

Command : Join

Select source object or multiple objects to join at once:

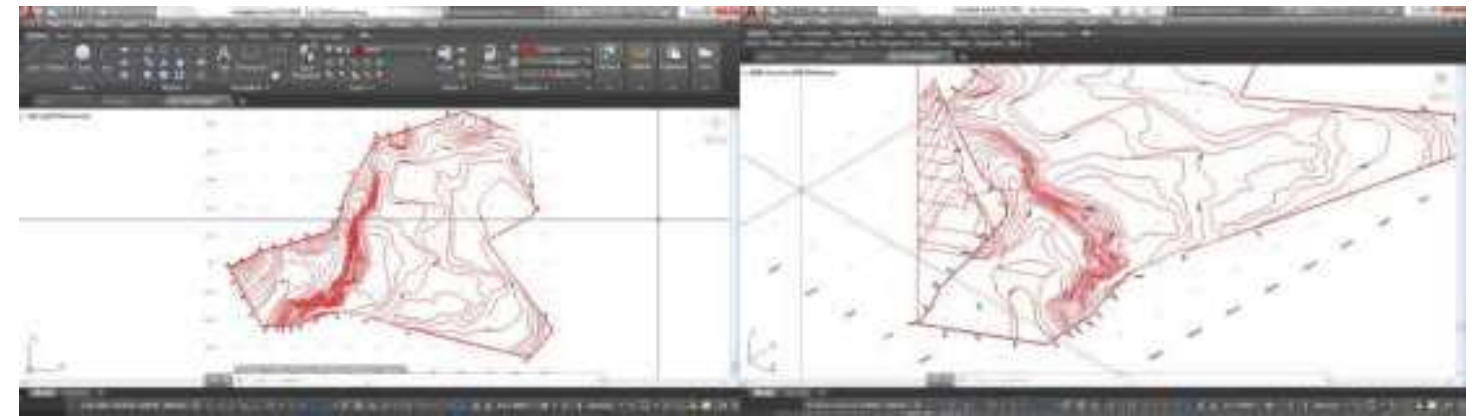

Hasil dari command join, menghasilkan panel-panel interval dalam 1 entity yang siap diberi volume.

Interval dalam 1 entity, diperlihatkan secara vertikal maupun secara horisontal. 


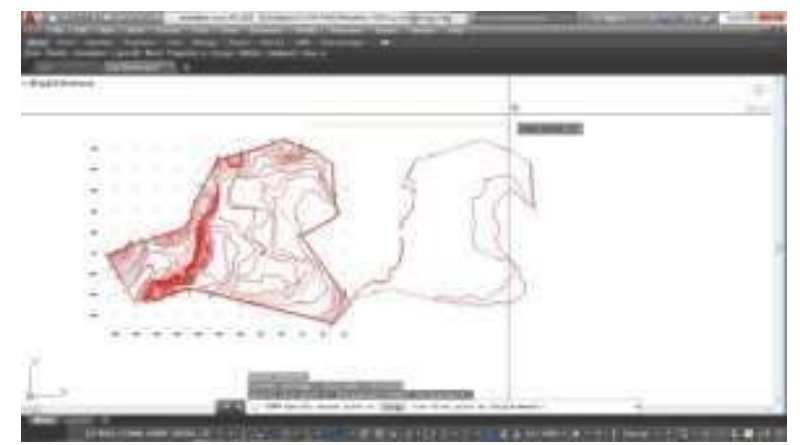

Langkah selanjutnya mengubah setiap interval kontur sesuai dengan elevasi masing-masing garis kontur.

Command : Change

Select objects: 1 found

Specify change point or [Properties]: $p$

Enter property to change

[Color/Elev/LAyer/LType/ltScale/LWeight/Thickness/TRansparency/Material/Annotative]: e

Specify new elevation $\langle 0.0000>$ : (Users Guide, 2017)

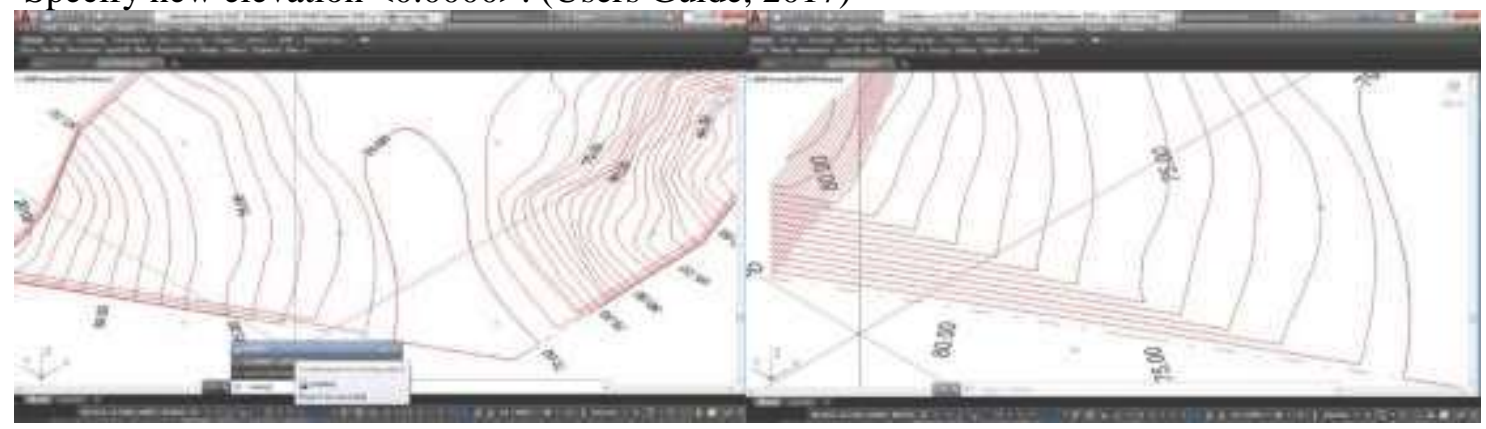

Elevasi garis kontur desesuaikan dengan hasil pengukuran ketinggian kontur.

Dilakukan pengecekan :

1. Apakah setiap garis kontur sudah digambar tanpa terlewatkan.

2. Apakah setiap garis kontur sudah terhubung.

3. Apakah elevasi setiap garis kontur sudah tepat.

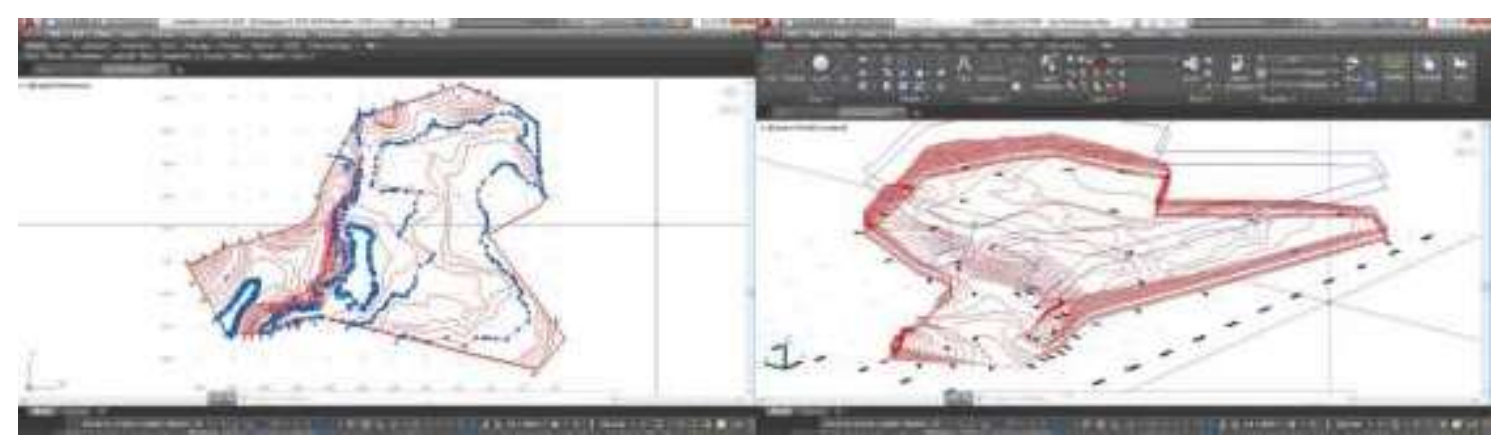

Kesalahan memasukan nilai elevasi menyebabkan tidak tepatnya kedudukan garis kontur.

Apabila ada elevasi yang keliru, kembali ke command Change elev. 


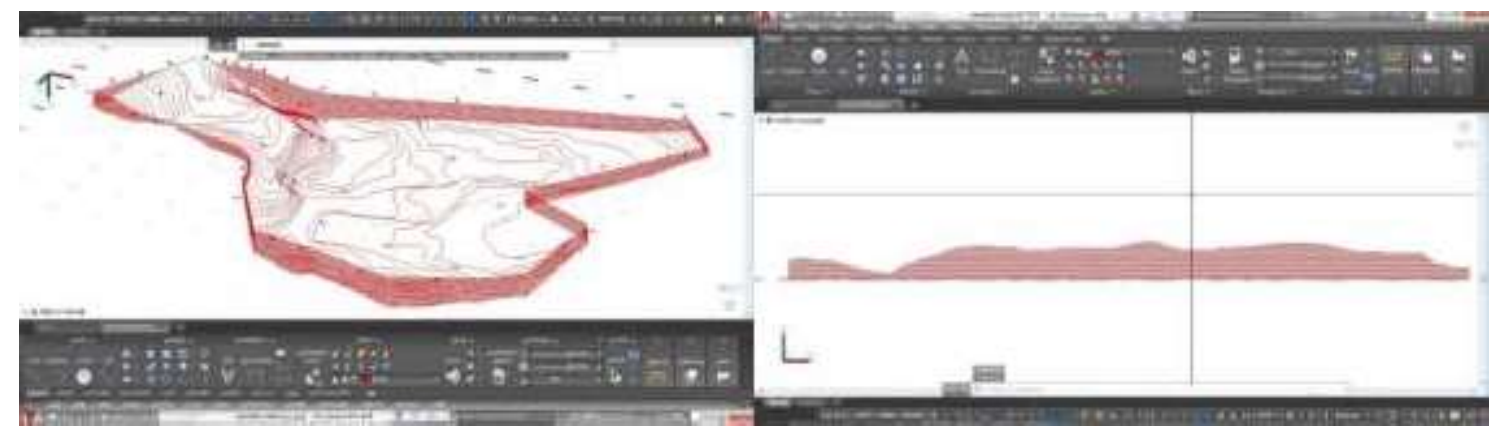

Hasil tampak depan apabila elevasi sudah tepat (Ansori, 2015).

Setelah elevasi tepat, masukan perintah 3D solid (Sholeh, 2015) :

Command : Extrude

Current wire frame density: ISOLINES $=4$, Closed profiles creation mode $=$ Solid

Select objects to extrude or [MOde]: 1 found

Select objects: enter

Specify height of extrusion or [Direction/Path/Taper angle]:

Masukan nilai negatif (-) agar tidak mengubah elevasi.

Lakukan terhadap 1 per 1 garis kontur.

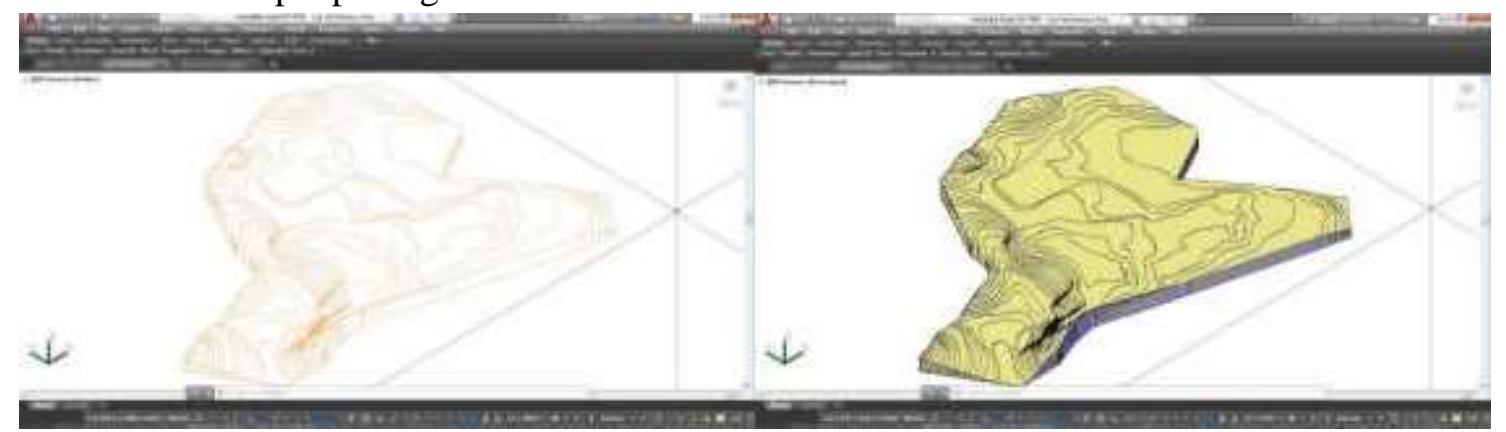

Hasil yang diperoleh setelah command extrude. Garis kontur telah memiliki volume sebagai obyek solid 3 Dimensi. Secara realistis atau terlihat secara nyata bentuk lahan hasil penggambaran garis kontur.

Akibat bentuk solid 3 Dimensi maka obyek lahan hasil penggambaran dapat dilihat dalam berbagai arah pandangan. (Sastra, 2019)

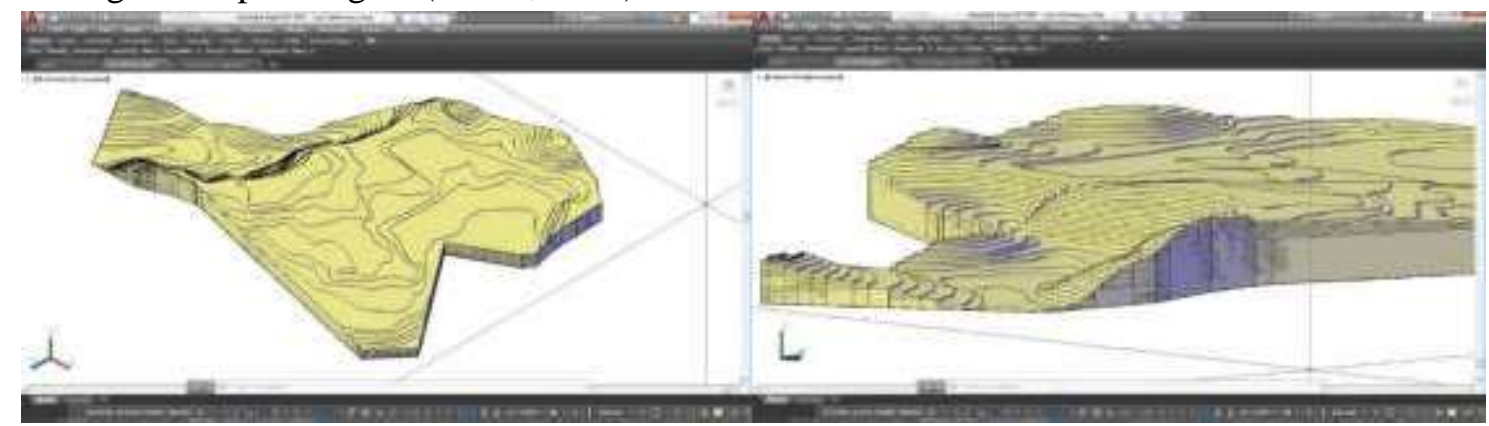

Untuk menghitung volume tanah / lahan digunakan command massprop. (Users Guide, 2017)

Command:_massprop

Select objects: Specify opposite corner: 40 found

Select objects:

SOLIDS 


$\begin{array}{ll}\text { Mass: } & 1487.8722 \text { dengan skala penggambaran } 1: 2000 \\ \text { Volume: } & 1487.8722 \\ \text { Bounding box: } & \text { X: } 89.4687 \text {---- } 112.7748 \\ & \text { Y: } 9.0103 \text {----26.5825 } \\ & \text { Z: }-0.0511 \text {--- } 1.3000 \\ \text { Centroid: } & \text { X: } 103.9664 \\ & \text { Y: } 18.0800 \\ & \text { Z: } 0.2637\end{array}$

Moments of inertia: $\mathrm{X}$ : 517452.6219

Y: 16104296.4163

Products of inertia: XY: -2800896.7591

YZ: -7201.7359

ZX: -40713.1724

Radii of gyration: $\quad X: 18.6489$

$\mathrm{Y}: 104.0371$

Z: 105.6941

Principal moments and X-Y-Z directions about centroid:

Press ENTER to continue:

Hasil perhitungan volume disesuaikan dengan skala penggambaran yaitu $1: 2000$

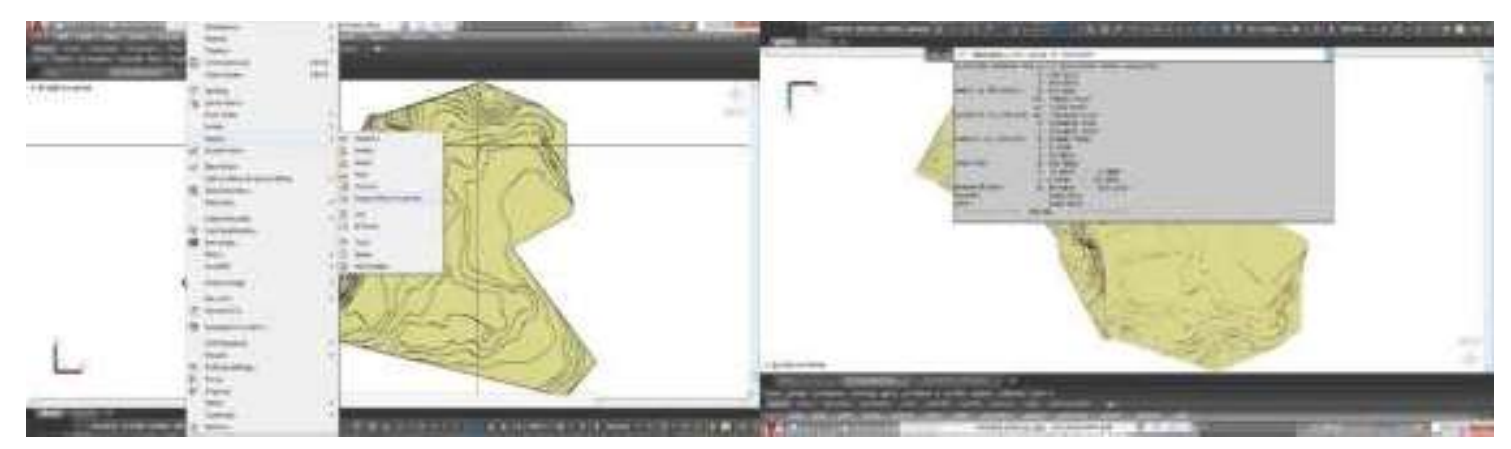

\section{KESIMPULAN}

Dari hasil yang diperoleh dapat disimpulkan beberapa hal, yaitu: Gambar yang baik akan tercipta apabila menggunakan kaidah gambar teknik dengan lengkap dan benar. Langkah menggambar garis kontur yang cepat dan praktis adalah menggunakan komputer. Masingmasing instruksi menuntut para drafter harus memiliki kemahiran menggambar garis kontur. Visualisasi gambar 3 dimensi secara nyata sekaligus menghitung volume hasil penggambaran diperlihatkan dengan cepat dan praktis. Kesalahan memasukan nilai elevasi menyebabkan tidak tepatnya kedudukan garis kontur.

\section{SARAN.}

Berdasarkan pelaksanaan penelitian ini ada beberapa hal yang disarankan, antara lain: Diperlukan penelitian lanjutan seperti perbandingan instruksi gambar teknik garis kontur menggunakan AutoCAD dan Mesin gambar. Dukungan sarana dan prasarana penelitian perlu 
diperhatikan agar dapat menunjang proses penelitian yang dilakukan.

\section{UCAPAN TERIMA KASIH}

Ucapan terimakasih disampaikan pada Politeknik Negeri Manado yang telah memberikan pendanaan dalam penelitian untuk skeman penelitian mandiri tahun 2020.

\section{DAFTAR PUSTAKA}

Ansori S, 2015, Desain 3d dengan AutoCAD 2015, PT Elex Media Komputindo, Jakarta.

Arikunto, Suharsimi, 1998, Prosedur Penelitian, Suatu Pendekatan Praktek, Rhineka Cipta, Jakarta.

Iskandar Muda, 2008, Teknik Survei Dan Pemetaan Jilid 3. Direktorat Pembinaan Sekolah Menengah Kejuruan Direktorat Jenderal Manajemen Pendidikan Dasar dan Menengah Departemen Pendidikan Nasional.

Laseau, Paul, 1980, Graphic Thinking for Architects and Designers Third Edition, Van Nostrand Reinhold Company, New York.

Manullang, Rio, 2014, Desain Rumah Dengan AutoCAD dan Google Sketchup, PT. Elex Media Komputindo, Jakarta.

Omura George, Brian C., 2017, Mastering AutoCAD 2018 and AutoCAD LT 2018, Benton, ISBN: 978-

$$
\text { 1-119-41425-4 }
$$

Rubenstein H., 1989, A Guide To Site And Environmental Planning, Utama Press.

Sastra Suparno, 2019, 3D Modeling Kreatif dengan AutoCAD, PT. Elex Media Komputindo, Jakarta.

Sholeh M, 2015, Tutorial AutoCAD, PT Informatika, Bandung.

Snyder J, Catanese A., 1984, Pengantar Arsitektur, Erlangga, Jakarta.

Soma, Aria, 2017, Mudah dan Cepat Menguasai AutoCAD 2D Release 2018, Elex Media Komputindo, Jakarta.

Soma, Aria, 1999, Mahir menggunakan AutoCad Release 14, buku 2, Elex Media Komputindo, Jakarta.

Tanaka, Eisuke, 1989, Architectural Presentation, Graphic-Sha Publishing Co. Ltd, Tokyo.

Users Guide, 2017, Autocad 2018, Autodesk.

Warren J. Luzadder \& Hendarsin H., 1986, Menggambar Teknik untuk Desain, Pengembangan Produk, dan Kontrol Numerik, Erlangga, Jakarta 